\title{
Effect of boat noise on the behaviour of bluefin tuna Thunnus thynnus in the Mediterranean Sea
}

\author{
G. Sarà ${ }^{1, *}$, J. M. Dean ${ }^{2}$, D. D'Amato ${ }^{1}$, G. Buscaino ${ }^{3}$, A. Oliveri ${ }^{1}$, S. Genovese ${ }^{3}$, \\ S. Ferro ${ }^{1}$, G. Buffa ${ }^{3}$, M. Lo Martire ${ }^{1}$, S. Mazzola ${ }^{3}$ \\ ${ }^{1}$ Dipartimento di Biologia Animale dell'Università, Via Archirafi 18, 90123 Palermo, Italy \\ ${ }^{2}$ Baruch Institute for Marine and Coastal Sciences, University of South Carolina, Columbia, South Carolina 29208, USA \\ ${ }^{3}$ Consiglio Nazionale delle Ricerche, Instituto per l'Ambiente Marino Costiero (CNR-IAMC), Via Vaccara 61, \\ 91026 Mazara del Vallo, Trapani, Italy
}

\begin{abstract}
The effect of boat noise on the behaviour of bluefin tuna Thunnus thynnus was investigated in the Egadi Islands, Sicily, during spring 2005 using a fixed tuna trap set near shipping routes. Tuna behaviour was observed when exposed to both natural ambient sound and sound generated by hydrofoil passenger ferries, small boats and large car ferries. Acoustical and behavioural analyses were conducted with and without extraneous sound to define a list of behavioural categories. Each vessel produced different engine sounds with regard to their composition and bandwidth, and all were distinctly different from ambient sound levels. In the absence of boat noise, tuna assumed a concentrated coordinated school structure with unidirectional swimming and without a precise shape. When a car ferry approached, tuna changed swimming direction and increased their vertical movement toward surface or bottom; the school exhibited an unconcentrated structure and uncoordinated swimming behaviour. Hydrofoils appeared to elicit a similar response, but for shorter periods. Agonistic behaviour was more evident when exposed to sounds from outboard motors of small boats. This study showed that local noise pollution generated by boats produced behavioural deviations in tuna schools. Schooling enhances tuna homing accuracy during their spawning migration, and an alteration in schooling behaviour can affect the accuracy of their migration to spawning and feeding grounds.
\end{abstract}

KEY WORDS: Bluefin tuna $\cdot$ Boat noise $\cdot$ Fish behaviour $\cdot$ Swimming $\cdot$ Schooling $\cdot$ Anthropogenic impact $\cdot$ Mediterranean Sea

\section{INTRODUCTION}

Over the last 2 decades, an increasing amount of evidence has shown that underwater sounds generated by human activities affect several types of responses in fish (Myrberg 1980, Engås et al. 1996, Bart et al. 2001, Smith et al. 2004, Popper et al. 2005, Sandstrom et al. 2005). Nevertheless, little is known to date on how noise pollution can affect the fitness of fish. Data are available for only a few species in response to a limited number of sounds under a narrow range of conditions, apart from some generic indications that fish exposed to excessive sound conditions may suffer reduced hearing (Popper et al. 2005). Such a reduction could result in fish being vulnerable to predators, make them less capable of locating prey, and hamper their ability to sense their entire acoustic environment (sensu Pitcher \& Parrish 1993). In addition, no specific studies have addressed the effects of underwater noise on customary natural behavioural patterns, probably because behavioural changes are generally assumed to be only temporary and quickly recoverable (Chapman 1976, Engås et al. 1996). Although there has been some evidence that different types of sound may elicit behavioural responses (e.g. avoidance, alarm, flight or startle in some fish species), a general scheme of fish behavioural response to extraneous sound conditions has yet to be better defined. In species belonging to the family Tunnidae, apart from the single observation about the hearing threshold of yellowfin tuna (Iversen 
1967), no data are available on the effect of sound on behaviour. This is surprising, as such species represent an economic resource of huge importance (Polovina 1996), but may be due to the fact that tuna behaviour can be difficult to study in the natural, pelagic environment. They form schools, migrate on an oceanic scale, and, being very large fish, pose difficult culture requirements in captivity and do not tolerate handling.

Tuna migration routes in the Mediterranean are mainly close to the coastline, often coinciding with intense commercial and recreational boat traffic. In these species, behaviour such as schooling has been identified as a strategy to enhance the accuracy of migration routes (sensu Kils 1986) and the efficiency of locating food (Pitcher \& Parrish 1993). Consequently, a behavioural deviation from common schooling patterns, potentially induced by noise pollution generated by vessels, could have significant effects on tuna behaviour and the threats to fitness might be very great. To this end, we recorded the behavioural responses of bluefin tuna Thunnus thynnus within a Mediterranean trap to different boat sounds. This was a unique opportunity to study their behaviour, albeit under semi-captive conditions. Our aims were: (1) to measure the frequency and intensity of sound generated by different types of boats, and (2) to analyse whether different sounds produced changes in both swimming and schooling behaviour.

\section{MATERIALS AND METHODS}

Study area. Acoustical and behavioural data were collected between May and June 2005 in the waters off Favignana Island (Egadi Archipelago, Western Sicily; Lat. $37.95^{\circ} \mathrm{N}$; Long. $12.3^{\circ} \mathrm{E}_{\text {; Fig. }}$ 1). A bluefin tuna trap has been positioned at the same site during each spring for at least the last 500 yr. Tuna schools migrating from the western basin of the Mediterranean Sea through the Tyrrhenian Sea enter a geographical triangle formed by the coastlines of Sicily (Trapani), Levanzo and Favignana Islands, where the trap off Favignana can capture them. The trap is anchored on the coast about $1000 \mathrm{~m}$ from the Favignana harbour and stretches along a coastal-offshore $\mathrm{N}-\mathrm{NW}$ transect up to $2000 \mathrm{~m}$ from the shore. The trap is composed of big 'room nets' (hereafter simply called the trap or experimental room of the trap) of about $70 \times 70 \mathrm{~m}$ (depth on average about $30 \mathrm{~m}$; total volume about 150000 to $180000 \mathrm{~m}^{3}$ ) into which the bluefin tuna are guided by means of a wide $(50 \mathrm{~cm}$ mesh) net wall, which is $36 \mathrm{~m}$ in depth. Only the harvest (experimental) room has a netted floor. The area is affected by commercial vessels and recreational boats travelling from Trapani to Levanzo and Favignana and vice versa from early morning $(07: 30 \mathrm{~h})$ to evening $(20: 00 \mathrm{~h})$. The boat traffic mainly comprises hydrofoil ferries carrying only passengers ( 2 engines of $\sim 2000 \mathrm{HP}$ each, hereafter referred to as hydrofoils), small boats (with outboard motors $~ 75$ to $100 \mathrm{HP}$ ) and large car ferries (hereafter referred to as ferries). The amount of commercial traffic was calculated using the timetables of the maritime companies, while the impact of small boat activity was estimated by direct observation.

Sound features establishing the conditions for experimental design. The experiment was designed to test whether the sound generated by different boat engines and propellers exceeded the ambient sound levels and thus affected tuna behaviour under conditions of semicaptivity. Experimental conditions were a priori fixed through pilot pre-surveys carried out some days before tuna entered the trap. This allowed us to study and analyse the sounds generated by the 3 types of vessels. The sound pressure spectra of the 3 vessels with respect to the background ambient spectrum is illustrated schematically in Fig. 2a. Hydrofoils produced the highest noise levels throughout the whole band (70 to $20000 \mathrm{~Hz}$ ) and, most importantly, produced a maximum of intense noise $(\sim 135 \mathrm{~dB}$ re $1 \mu \mathrm{Pa}$, measured at $360 \mathrm{~m}$ by hy-

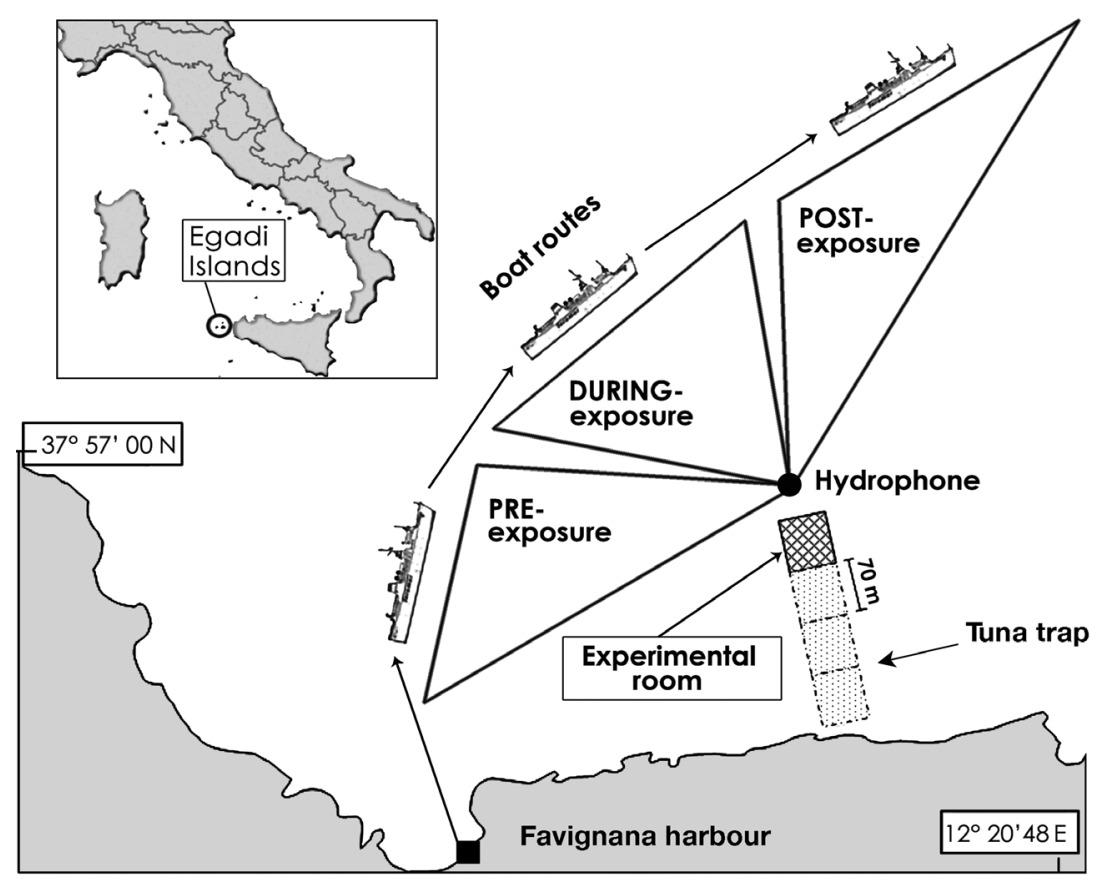

Fig. 1. Map (not to scale) of study area (Egadi Islands, Sicily) showing boat routes and position of the tuna trap and hydrophone site. 

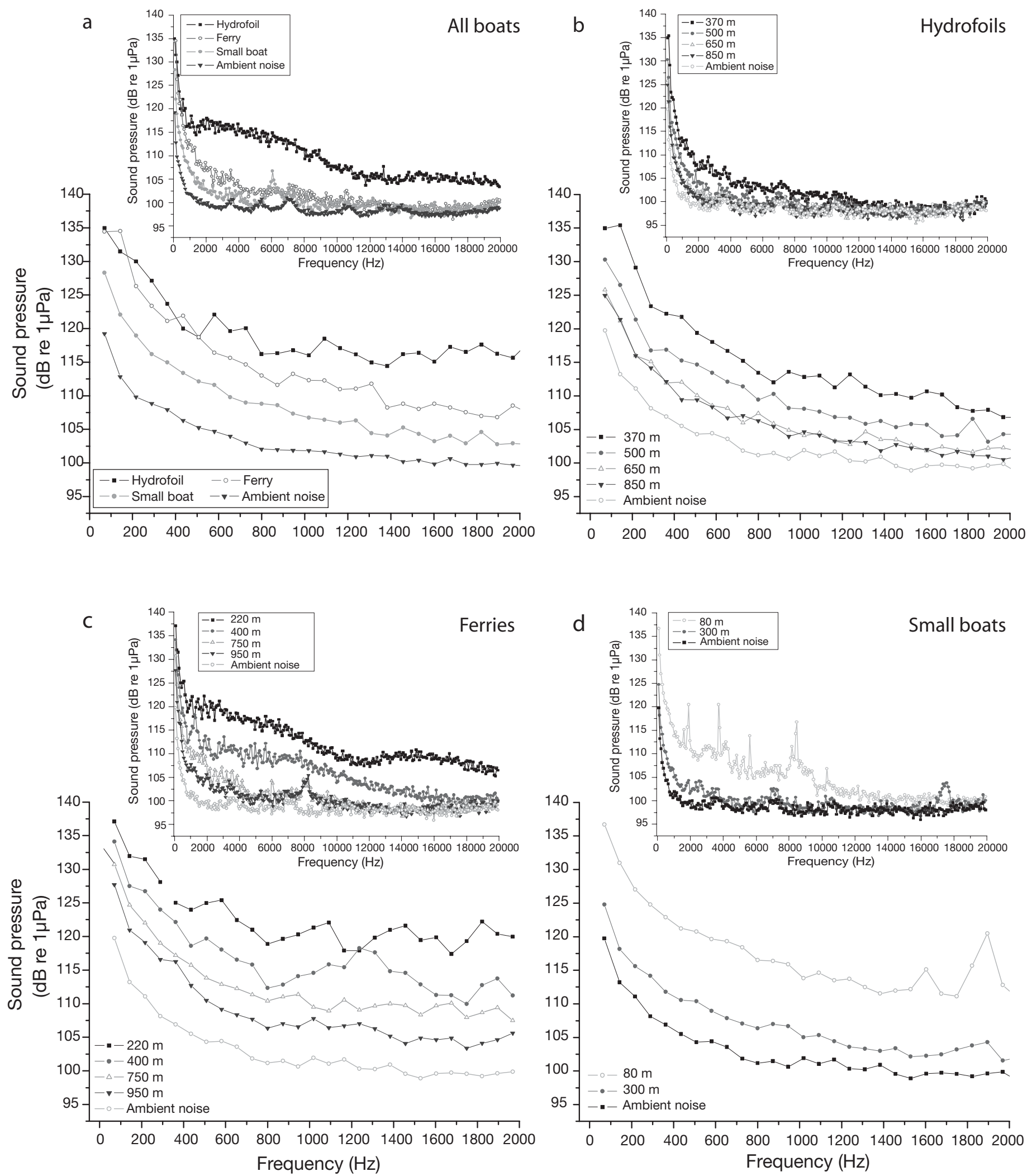

Fig. 2. Sound pressure spectra in the bandwidth 70 to $2000 \mathrm{~Hz}$, and (insets) 70 to $20000 \mathrm{~Hz}$ generated by (a) all tested boats (measured at $360 \mathrm{~m}$ from hydrophone for hydrofoils and ferries and at about $100 \mathrm{~m}$ for small boats) and the ambient noise level (control); with detailed distance attenuation of (b) hydrofoils, (c) ferries and (d) small boats 
drophone) at low frequencies. The ferries produced the second highest noise levels ranging between 4000 and $6000 \mathrm{~Hz}$, and were always more intense than both small boat and background noise. Small boats produced the lowest noise levels of the 3 , which in the range of 4000 to $6000 \mathrm{~Hz}$ were always greater than ambient noise. Details of attenuation as the hydrofoils moved away from the hydrophone are shown in Fig. 2b. Spectral analysis showed that hydrofoil noise was peaking at about 200 to $400 \mathrm{~m}$ from the hydrophone, while after about 500 to $600 \mathrm{~m}$ they attenuated to close to the ambient level, especially between 6000 and $20000 \mathrm{~Hz}$. Ferries generated the highest noise levels at about $370 \mathrm{~m}$ from the hydrophone (Fig. 2c), while after $500 \mathrm{~m}$ the noise level was similar to the ambient level. Small boats generated the highest noise up to $300 \mathrm{~m}$ from the hydrophone (Fig. 2d) at the lowest frequencies, while further than $300 \mathrm{~m}$, their noise level was more or less the same as the ambient level. Therefore, the maximum noise level was recorded when each vessel was about 200 to $300 \mathrm{~m}$ from the hydrophone. By the time they reached a distance of about $700 \mathrm{~m}$ from the hydrophone, the noise level was no different to that of the background. We thus defined the phases of our experiment as pre-, during- and post-boat passage exposure and carried out observations to measure response of tuna to the different boat sounds. The pre-phase started when the vessels were not yet visible and lasted for $\sim 10 \mathrm{~min}$, until the boats were approximately 700 to $1000 \mathrm{~m}$ from the hydrophone. The duringphase began when the boats were about 500 to $700 \mathrm{~m}$ from the hydrophone (about 600 to $800 \mathrm{~m}$ from the experimental room of the trap) and lasted throughout the duration of travel past the trap (from 100 to $200 \mathrm{~m}$ for small boats to 400 to $600 \mathrm{~m}$ for ferries and hydrofoils) and stopped when the vessels were more than 700 to $800 \mathrm{~m}$ away from hydrophone. The post-phase followed the end of the during-phase and lasted for some $10 \mathrm{~min}$ more (Fig. 1). Control conditions were standardised in order to carry out behavioural data collection when no boat had passed the trap for at least $120 \mathrm{~min}$. Even if no boats passed during these control trials, we carried out measurements and divided the session into virtual pre-, during- and post-phases, which were of the same length as the experimental pre-, during- and postphases.

Bioacoustical measurements. Acoustical measurements were carried out from a boat anchored to the top of the tuna trap (Fig. 1; depth $\sim 32 \mathrm{~m}$ ) close (only a few metres) to the experimental tuna room ( 100 to $400 \mathrm{~m}$ from the point closest to the boat route) using a broadband spherical hydrophone (TC4034, Reson) positioned at a mean depth of about $5 \mathrm{~m}$, providing uniform omni-directional characteristics over a wide frequency range of 1 to $480 \mathrm{kHz}$. The hydrophone was connected to a $1 \mathrm{MHz}$ bandwidth single ended voltage preamplifier (VP1000, Reson) with variable range (from 0.0 to $32.0 \mathrm{~dB}$; tolerance $\pm 0.5 \mathrm{~dB}$ ), interpolated with a noise filter with a variable cut-off (from 0.1 to $50 \mathrm{kHz}$ ) and a multifunction data acquisition card (Ni DAQCard-6062E, National Instruments). The hardware was capable of measuring sound in a variable field between 0.1 and $100 \mathrm{kHz}$. Sound signals obtained in the field were elaborated with a routine developed by the Inter-disciplinary Group of Oceanography (GIO at CNR-IAMC, Mazara del Vallo, Italy) using LabView rel. 7.0 Express software (National Instruments). Distances to the boats were measured by radar (1000 MK II, JRC).

Behavioural observations. Behavioural observations were carried out during 2 periods: 19 to 27 May and 14 to 19 June 2005. During these periods, 2 different schools, each of about 50 tuna (total weight $40.5 \pm$ $21.0 \mathrm{~kg}$ and $54.0 \pm 4.9 \mathrm{~kg}$, respectively), entered the trap. In order to avoid interference from any kind of stress, measurements were not started until 2 to $3 \mathrm{~d}$ after the tuna had entered the trap to allow the tuna

Table 1. Thunnus thynnus. Description of behaviour types: swimming and shape and structure of tuna schools

\begin{tabular}{|lll|}
\hline \multirow{2}{*}{ Swimming } & Lescription of behaviour \\
& $\begin{array}{l}\text { Surface swimming } \\
\text { Middle column swimming }\end{array}$ & School swims close to surface \\
& Horizontal swimming & School swims at about 10 m down from surface \\
& Swimming toward surface & School swims horizontally \\
& Swimming toward bottom & School swims vertically towards surface \\
& Direction change & Direction change in swimming of tuna group \\
& Speed increase & School increases swimming speed \\
Schooling & Polarised-no shape & Unshaped school swimming in the same direction \\
& Polarised-wedge shaped school & Wedge shaped school swimming in the same direction \\
& Polarised-ball shaped school & Ball shaped school swimming in the same direction \\
& Interaction & A fish swims toward another individual's tail with its mouth open \\
& Loose school & Unshaped school whose individuals swim in different directions \\
& Undirected & Fish swim individually with reduced velocity and are not part of a school \\
\hline
\end{tabular}


some acclimatisation to the semicaptive conditions (Mork et al. 1999, Romero 2004, Westerberg et al. 2004).

Observations were carried out using 3 SONY Hi-8 video cameras encapsulated in waterproof boxes (NIMAR). Video cameras were managed by SCUBA divers, who were always positioned downstream of the prevailing current and in the best positions to observe as much of the experimental room as possible, and all tuna moving anywhere in the room. Data obtained from video images were analysed and combined with direct behavioural observation data recorded by divers using pencils and waterproof tables. SCUBA divers were blind to the session type (i.e. they were unaware of whether a certain session was control or treatment) and data were coded from videotape by an observer who was also blind to the treatment conditions for each trial (Sloan \& Hare 2004). As the different types of tuna behaviour had not been previously described in the scientific literature, we used pre-survey sessions (carried out between May 15 and 18) with and without extraneous sound in order to define a list of behavioural variables (i.e. ethogram) for the analyses (Table 1).

For each group, in the presence of each sound type and the absence of extraneous sound conditions, 2 measurement sessions were conducted. An operator positioned close to the tuna trap used binoculars and radar to manage the timing of each session and information on the distance of each boat from the hydrophone. Tuna behavioural response, in absence of extraneous boat sound (hereafter called control treatment), was measured throughout the experimental period. Behavioural measurements in each session started $10 \mathrm{~min}$ after the divers had reached their assigned position and had fixed the video cameras in the tuna trap. This familiarised the fish with the divers' presence (Romero 2004, Westerberg et al. 2004). Data were collected using the focal sampling method (Martin \& Bateson 1993), and the analysed interval length for each phase was $5 \mathrm{~min}$. Data for analysis were extracted from the behavioural event matrix and the number of events came from a 5 min length interval for each phase.

Statistical analyses. Behavioural data were analysed in order to test the null hypothesis, i.e. that there was no difference in tuna behaviour when exposed to the 3 different types of sound, using a 4-way ANOVA. Thus, Sound (control, ferry, hydrofoil and small boat vs. absence of sound: 4 levels) and Phase (pre-, during- and post-passage exposure: 3 levels) were treated as fixed factors in the experimental design. Two different and independent homogeneous tuna schools (School, 2 levels) and 2 different sessions of measurement carried out within a couple of days of each other (Session: 2 levels) were treated as random factors and nested in the interaction of Sound $\times$ Phase. Two trials $(n=2)$ were chosen randomly for each session. We were aware that the design carried the risk of pseudo-replication (sessions which are not independent; Hurlbert 1984), but establishing 2 measurement sessions in $2 \mathrm{~d}$ for the same school allowed us to further test whether tuna changed their behaviour due to their semi-captive conditions. As there are no data to indicate that a habituation process to conditions of semicaptivity might elicit a behavioural change, we considered the risk of pseudo-replication less important than the opportunity of obtaining information on tuna behaviour over time (Oksanen 2001).

For all analyses, the heterogeneity of variance was tested using Cochran's C-test prior to the ANOVA, and the Student-Newman-Keuls (SNK) test allowed the appropriate means comparison. GMAV rel 5.0 (University of Sydney, personally licensed to G. Sarà) was used to perform ANOVAs.

\section{RESULTS}

Behavioural variables measured under different treatments are reported in Table $2 \mathrm{a}, \mathrm{b}$. Sound affected the position of tuna in the water column. The tuna under control conditions swam horizontally in a 'cruis- 


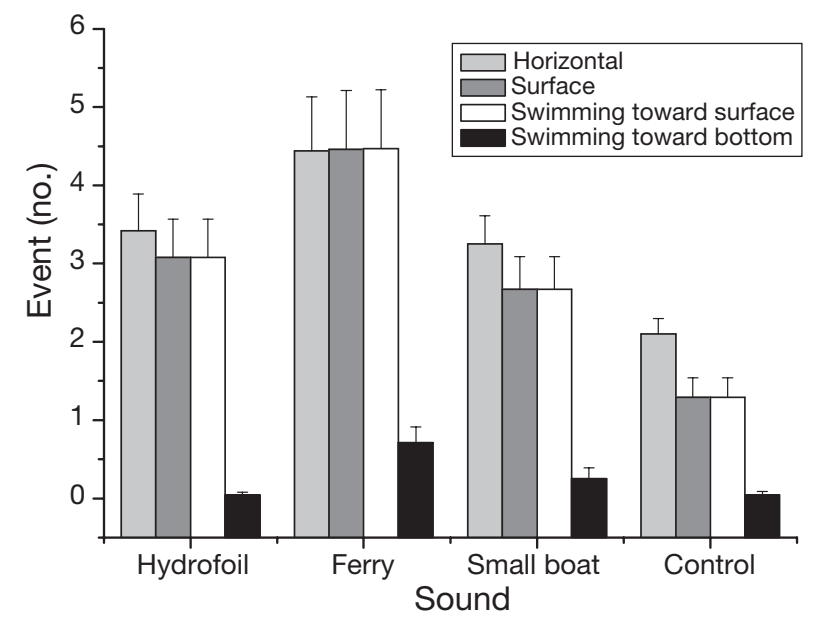

Fig. 3. Thunnus thynnus. Changes in tuna surface swimming; middle column swimming; swimming toward surface; and swimming toward bottom behaviours as a function of different boat sounds. (SNK tests for all 4 variables: ferry $>$ hydrofoil $=$ small boat $=$ control). Event: means; error bars: + SE

ing' mode in mid-water, about 12 to $15 \mathrm{~m}$ from the surface (Fig. 3). They rarely moved from the mid-water column to the surface under no-noise conditions, and, similarly, they rarely descended towards the bottom. By contrast, when a boat approached (ANOVA, p < 0.05; Table $3 \&$ Fig. 3), the tuna significantly increased their vertical movement towards the surface or the bottom (ANOVA, p < 0.05; Table 3 \& Fig. 3). Ferry noise seemed to most affect the movements and position of tuna in the water column (ANOVA, p < 0.05; Fig. 4), followed by hydrofoil and lastly the outboard motordriven small boat noise. In addition, the tuna showed changes in swimming direction (ANOVA, p $<0.05$; Table 3); this behaviour was mainly associated with noise generated by hydrofoil and ferry. They also showed a modest increase in swimming speed (ANOVA, p > 0.05) mainly associated with noise generated by small boats.

Boat noise also had an effect on the structure of the schools. In the absence of noise, tuna usually assumed a polarised school with no consistent shape (ANOVA, p < 0.05; Table 4 \& Fig. 5) but maintaining movement in the same direction. Less frequently, they assumed a shape (e.g. ball or a wedge; these 2 variables were pooled and analysed together), a structure which was significantly more frequent in the controls (ANOVA, p $<0.05$; Table 4 \& Fig. 5). The school's tendency to lose concentration increased under ferry noise conditions (ANOVA, $\mathrm{p}<0.05$; Table 4 \& Fig. 5), when unidirectional movements significantly decreased (ANOVA, $\mathrm{p}<0.05$; Table 4 \& Fig. $6)$. The tuna also appeared to increase interactions among themselves (ANOVA, p $<0.05$; Table 4 \& Fig. 6) when subjected to the higher frequencies of the during- and post-phases of small-boat passages. In all analyses, no differences between the sessions were detected (ANOVA; p > 0.05; Tables $3 \& 4$ ), but a general difference was evident among groups (apart from some swimming variables; Tables $3 \& 4$ ). The number of altered behaviour types significantly

Table 3. Thunnus thynnus. ANOVA carried out on 'swimming variables' to test the null hypothesis of no difference among boat sounds and controls throughout different phases of the study (pre-, during- and post-phase). ns $=$ no significant difference; ${ }^{*}=$ difference at $\mathrm{p}<0.05_{;}{ }^{* *}=$ difference at $\mathrm{p}<0.01{ }^{* * *}=$ difference at $\mathrm{p}<0.001 ; \xi=$ data transformed to $\log (\mathrm{x}+1)$; $\#$ behaviours $=$ total number of recorded behaviours as an expression of behavioural diversity. For definition of swimming behaviour variables see Table 1

\begin{tabular}{|c|c|c|c|c|c|c|c|c|c|c|c|c|c|}
\hline \multirow[t]{2}{*}{ Source of variation } & \multirow[b]{2}{*}{ df } & \multicolumn{3}{|c|}{ Surface } & \multicolumn{3}{|c|}{ Middle column } & \multicolumn{3}{|c|}{ Horizontal } & \multicolumn{3}{|c|}{ Toward surface } \\
\hline & & MS & $F$ & $p$ & MS & $F$ & $\mathrm{p}$ & MS & $F$ & $\mathrm{p}$ & MS & $F$ & $\mathrm{p}$ \\
\hline Sound (So) & 3 & 2.9 & 3.5 & * & 1.6 & 1.0 & ns & 0.8 & 2.1 & ns & 8.2 & 11.7 & $* * *$ \\
\hline Phase (Ph) & 2 & 3.6 & 4.4 & * & 3.3 & 2.1 & ns & 3.1 & 8.7 & ${ }^{*}$ & 1.4 & 2.1 & $\mathrm{~ns}$ \\
\hline School (Gr) & 12 & 0.8 & 18.5 & $*$ & 1.6 & 1.4 & ns & 0.4 & 4.4 & $*$ & 0.7 & 2.4 & $*$ \\
\hline Session $($ So $\times \mathrm{Ph} \times \mathrm{Gr})$ & 24 & 0.0 & 0.2 & ns & 1.1 & 0.9 & ns & 0.1 & 0.6 & ns & 0.3 & 0.6 & ns \\
\hline So $\times \mathrm{Ph}$ & 6 & 0.7 & 0.9 & ns & 2.2 & 1.4 & ns & 0.6 & 1.6 & ns & 0.7 & 1.0 & ns \\
\hline Residuals & 48 & 0.2 & & & 1.3 & & & 0.1 & & & 0.5 & & \\
\hline Cochran's $C$-test & & & & $\xi$ & & & ns & & & $\xi$ & & & ns \\
\hline \multirow[t]{2}{*}{ Source of variation } & & \multicolumn{3}{|c|}{ Toward bottom } & \multicolumn{3}{|c|}{ Direction change } & \multicolumn{3}{|c|}{ Speed increase } & \multicolumn{3}{|c|}{ \# Behaviours } \\
\hline & df & MS & $F$ & $\mathrm{p}$ & MS & $F$ & $\mathrm{p}$ & MS & $F$ & $\mathrm{p}$ & MS & $F$ & $\mathrm{p}$ \\
\hline Sound (So) & 3 & 2.4 & 9.1 & ${ }^{* * *}$ & 9.1 & 2.5 & ns & 3.5 & 2.0 & ns & 22.9 & 7.8 & ** \\
\hline Phase (Ph) & 2 & 2.6 & 10.1 & ** & 34.1 & 9.2 & * & 2.3 & 1.3 & ns & 10.7 & 3.7 & * \\
\hline School (Gr) & 12 & 0.3 & 0.8 & ns & 3.7 & 1.2 & ns & 1.7 & 2.9 & ns & 2.9 & 3.1 & * \\
\hline Session $($ So $\times \mathrm{Ph} \times \mathrm{Gr})$ & 24 & 0.3 & 1.6 & ns & 3.1 & 1.8 & ns & 0.6 & 2.0 & ns & 0.9 & 0.7 & ns \\
\hline So $\times \mathrm{Ph}$ & 6 & 1.4 & 5.5 & ${ }^{* *}$ & 9.6 & 2.6 & $*$ & 1.0 & 0.6 & ns & 3.3 & 1.1 & $\mathrm{~ns}$ \\
\hline Residuals & 48 & 0.2 & & & 1.7 & & & 0.3 & & & 1.4 & & \\
\hline Cochran's $C$-test & & & & $\xi$ & & & ns & & & ns & & & ns \\
\hline
\end{tabular}




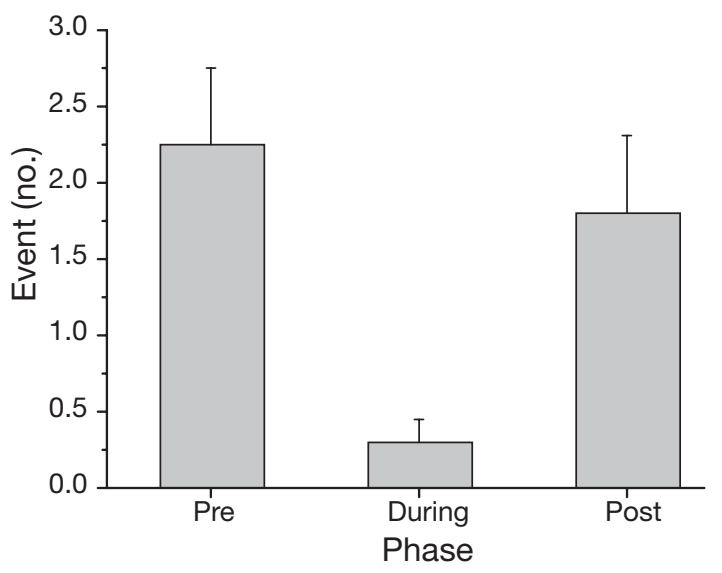

Fig. 4. Thunnus thynnus. Effect of ferry noise on middle column position of tuna throughout the exposure phases (SNK test: during $<$ pre $=$ post). Event: means; error bars: + SE

increased under ferry noise conditions, while it was minimal under control conditions (ANOVA, p $<0.05$; Table 4 \& Fig. 7).

\section{DISCUSSION}

\section{Tuna behavioural responses under control conditions}

In the absence of boat noise, tuna behaviour appeared to be very calm, exploiting the available water column mainly at its middle level at about 10 to

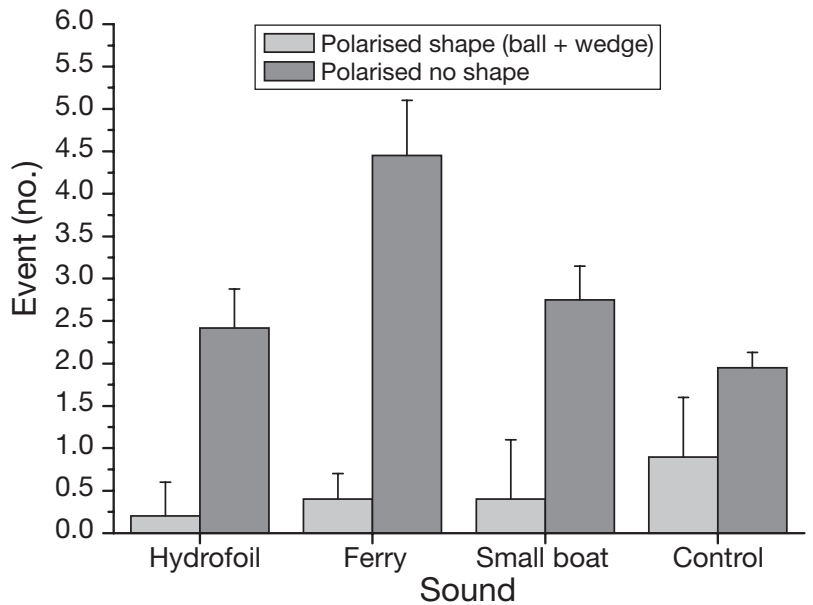

Fig. 5. Thunnus thynnus. Tuna school shape changes as a function of different boat sounds (SNK test for polarised no shape: ferry $>$ hydrofoil $=$ small boat $=$ control ; SNK test for polarised ball wedge shape: control $>$ ferry $=$ hydrofoil $=$ small boat $)$. Event: means; error bars: + SE

$15 \mathrm{~m}$ from the surface, swimming slowly and horizontally, mostly circularly around the walls of the trap nets. With the exception of aerial photos (Lutcavage \& Kraus 1995) and photos taken by some national fishery agencies, there are no effective data available in the current literature that describe the swimming behaviour and shape of tuna schools, both in captivity and in the natural environment. By means of ultrasonic telemetry experiments close to fish aggregating devices (FAD) and with archival and pop-up satellite

Table 4. Thunnus thynnus. ANOVA carried out on 'school variables' to test the null hypothesis of no difference among boat sounds and controls throughout different phases of the study (pre-, during- and post-phase). ns $=$ no significant difference; ${ }^{*}=$ difference at $\mathrm{p}<0.05{ }^{* *}=$ difference at $\mathrm{p}<0.01 ;{ }^{* * *}=$ difference at $\mathrm{p}<0.001 ; \xi=$ data transformed to $\log (\mathrm{x}+1) ;$; behaviours $=$ total number of recorded behaviours as an expression of behavioural diversity. For definition of school behaviour variables see Table 1

\begin{tabular}{|c|c|c|c|c|c|c|c|c|c|c|}
\hline & \multirow[b]{2}{*}{$\mathrm{df}$} & \multicolumn{3}{|c|}{ Polarised no shape } & \multicolumn{3}{|c|}{ Polarised ball + wedge shape } & \multicolumn{3}{|c|}{ Loose } \\
\hline & & MS & $F$ & $p$ & MS & $F$ & $\mathrm{p}$ & MS & $F$ & $\mathrm{p}$ \\
\hline Sound (So) & 3 & 28.5 & 8.3 & ** & 2.5 & 4.7 & * & 0.0 & 0.7 & ns \\
\hline Phase (Ph) & 2 & 50.8 & 14.9 & ** & 0.4 & 0.8 & ns & 0.1 & 1.0 & ns \\
\hline School (Gr) & 12 & 3.4 & 1.2 & ns & 0.5 & 1.2 & ns & 0.1 & 1.8 & ns \\
\hline Session $($ So $\times \mathrm{Ph} \times \mathrm{Gr})$ & 24 & 2.9 & 1.3 & ns & 0.5 & 0.6 & ns & 0.0 & 0.8 & $\mathrm{~ns}$ \\
\hline So $\times \mathrm{Ph}$ & 6 & 23.1 & 6.8 & ** & 0.3 & 0.5 & ns & 0.0 & 0.7 & ns \\
\hline Residuals & 48 & 2.2 & & & 0.8 & & & 0.0 & & \\
\hline \multirow[t]{2}{*}{ Cochran's $C$-test } & & & & ns & & & $\xi$ & & & $\xi$ \\
\hline & & \multicolumn{3}{|c|}{ Interaction } & \multicolumn{3}{|c|}{ Undirected } & \multicolumn{3}{|c|}{ \# Behaviours } \\
\hline Source of variation & $\mathrm{df}$ & MS & $F$ & $\mathrm{p}$ & MS & $F$ & $\mathrm{p}$ & MS & $F$ & $\mathrm{p}$ \\
\hline SOUND (So) & 3 & 0.3 & 3.8 & * & 8.8 & 6.1 & ** & 24.8 & 1.7 & ns \\
\hline PHASE (Ph) & 2 & 0.0 & 0.2 & ns & 8.9 & 6.1 & $*$ & 73.9 & 5.1 & * \\
\hline School (Gr) & 12 & 0.1 & 1.6 & ns & 1.5 & 1.7 & ns & 14.6 & 1.7 & ns \\
\hline Session $($ So $\times \mathrm{Ph} \times \mathrm{Gr})$ & 24 & 0.0 & 0.5 & ns & 0.9 & 0.9 & ns & 8.8 & 1.7 & ns \\
\hline So $\times \mathrm{Ph}$ & 6 & 0.1 & 1.1 & ns & 2.2 & 1.5 & ns & 52.1 & 3.6 & ${ }^{*}$ \\
\hline Residuals & 48 & 0.1 & & & 1.0 & & & 5.3 & & \\
\hline Cochran's $C$-test & & & & $\xi$ & & & $\xi$ & & & \\
\hline
\end{tabular}




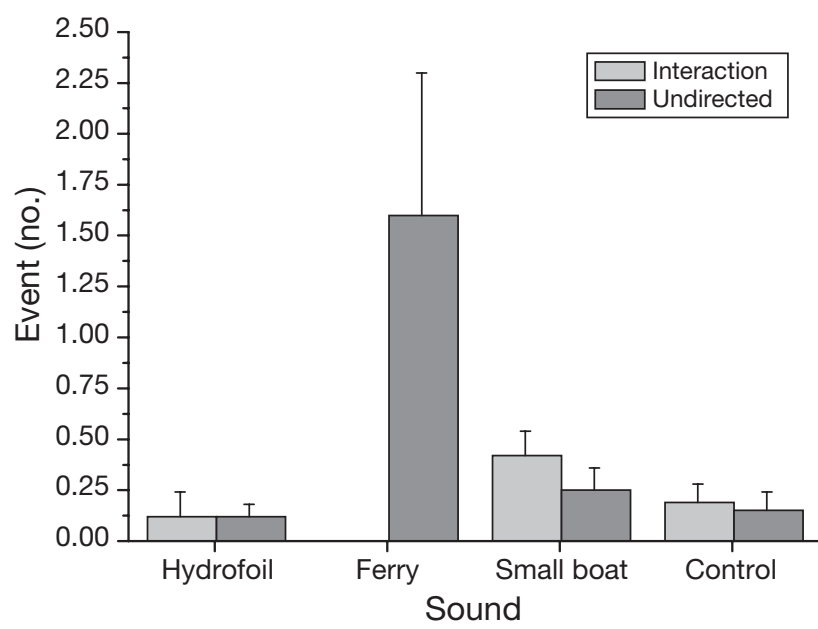

Fig. 6. Thunnus thynnus. Interactions and undirected movements elicited by different boat sounds (SNK tests for interactions: small boat $>$ ferry $=$ hydrofoil $=$ control; for undirected: ferry $>$ hydrofoil $=$ small boat $=$ control). Event: means; error bars $+\mathrm{SE}$

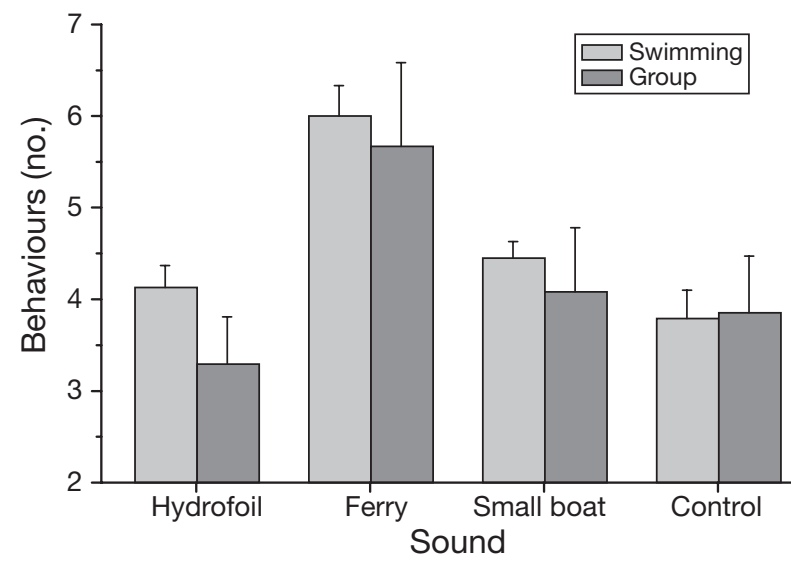

Fig. 7. Thunnus thynnus. Total number of behaviours manifested by tuna schools as elicited by different boat sounds (SNK tests for both swimming and group behaviours: ferry $>$ hydrofoil $=$ small boat $=$ control) . Event: means; error bars: + SE

tags, tropical tuna have been observed to swim mainly horizontally for most of the time (sensu Colgan 1993, Magurran 1993, Dagorn et al. 2000a). Furthermore, it is known that they swim vertically when they change water layers, probably as a response to internal stimuli (feeding, thermoregulation, diurnal cycle or migration; Dagorn et al. 2000b, Block et al. 2005). An increase in swimming speed and abrupt direction changes (i.e. turning behaviour) in fish has been thought to be associated with migratory behaviour (Block et al. 2005) and foraging behaviour (prey hunting; Benhamou 1992, Josse et al. 1998, Marsac \& Cayré 1998, Dagorn et al. 2000a,b, Domenici et al. 2000), and as a response to external stimuli such as the threat of a predator encounter (Pitcher \& Parrish 1993). In the present study, the observed circular swimming pathway around the net walls was probably a response to semicaptivity. However, the tuna did not come into contact with the net wall while swimming and did not attempt to pass through it, which indicated no distress at their environment.

We can only speculate on the interpretation of school shape and dynamics, because no observations exist in the current literature due to the great difficulty of directly observing tuna in nature. Tuna are known to school (Pitcher \& Parrish 1993, Sharp 2001), and our semi-captive controls would confirm such an observation. Indeed, tuna appeared to spend most of their time in the trap nets as an unshaped but polarised school. On various occasions, they tried to form a school shaped either like a ball or a wedge. The meaning of these different shapes is not yet clear. Nevertheless, different school shapes could be an effective defence, representing fish responses to predator threats (Pitcher \& Parrish 1993). For example, herrings in the wild, when encircled by killer whales, formed highly compacted schools (Domenici et al. 2000). Attempts by tuna to form schools in captivity could be considered as a response to every type of threat. However, the dynamics of schooling in fish in response to predation threats are generally associated with fast-moving, turning behaviour and burst speed (Keenleyside 1955, Domenici \& Blake 1997). In our study, tuna observed forming schools under experimental conditions did not show abrupt speed changes and turning behaviour. Adult tuna are large piscivores who encounter few threats from predators in the wild. Thus, the schooling by the bluefin tuna is more likely to represent a behavioural function for enhancing success in the search for food (Pitcher \& Parrish 1993) or for gaining advantages during migration (Kils 1986). Consequently, we can only hypothesise that the tuna schooling in the trap could have been due to (1) a stereotyped result of captivity or (2) a behaviour associated with foraging or (3) a simple attempt to gain the best cruising configuration for energy conservation. Nevertheless, the formation of behavioural linkages, distance between individuals, swimming dynamics, motivations for schooling and other factors are still open questions, and further studies are needed to understand the school dynamics of this species in the absence of external anthropogenic stimuli.

\section{Tuna behavioural responses to extraneous sound conditions}

Boat engine noise elicited significantly different behavioural responses from bluefin tuna than nonoise controls. These behavioural differences proba- 
bly allow us to exclude the possibility that behavioural responses elicited by excessive noises could be due to captivity. The effects of sound on behavioural traits also appeared to have a significant influence on the swimming behaviour of tuna, their spatial position in the water column and their group structure. Under conditions of exposure to boat engine sounds, tuna increased their vertical movements in the water column, abandoning the middle layer and tending to reach the surface but with rare, though significant, movements towards the bottom layers. Although we did not document sound at different depths within the experimental room and the tuna were captive, such a behavioural response appeared to be suggestive of avoidance behaviour and movement away from the sound source (Popper 2003). Avoidance has rarely been described in fish as a possible response to noise (but see Chapman 1976) generated by boat propellers (Boussard 1981, Pearson et al. 1992, sensu Popper 2003). Although not much specific evidence is available of fish behavioural responses to extraneous sound conditions, some earlier studies have indicated that low frequency sounds elicit an avoidance reaction in cod (e.g. Hawkins \& Chapman 1975) and a similar response in 2 other species of the Gadidae family (Chapman 1976). These data suggest that the ferry noise in our study did elicit apparent avoidance behaviour, as the tuna seemed to try to move away from the noise source but, unable to find an escape path, were forced to change water levels. In addition, the tuna appeared to display a rather non-directional reaction, which led to the dispersion of the school in the net pen. Thus the sound produced by ferries may create a physiological alteration, causing some kind of confusion. Whether this is so is still unknown, because the appropriate experiments have not yet been carried out.

Hydrofoils elicited a similar response to ferries, but the speed of the approaching vessel was very fast, and the resulting effects on tuna behaviour very rapid both in appearance and disappearance. Thus, under hydrofoil noise conditions, the tuna reacted exactly as they did under ferry conditions, albeit for a shorter period of time. The outboard motors of small boats generate a high frequency cavitation noise, which appears to affect behaviour response in fish. For example, highspeed boats produced sounds eliciting a flight response in 2 cyprinid species (Boussard 1981). Under similar conditions, tuna also appear to be restless, making quick speed changes and abrupt turning behaviour. They tend to spend most of their time near the surface and tend to abandon the concentrated school behaviour. Thus, this type of sound can elicit a response similar to the escape behaviour induced by an encounter with a predator. The behavioural response of a fish to threat comprises the following stages: detection of threat, its preliminary avoidance and, finally, escape (Godin 1997, Smith 1997). In the case of our semi-captive tuna, only the escape behaviour could be detected, due to the very short duration of the high-frequency sound.

\section{CONCLUSIONS}

The experiments in this study were not specifically conducted to study the auditory abilities of tuna. Nevertheless, ours would appear to be one of the first studies to investigate the responses of a fish species to sounds over a broad range of frequencies (sensu Popper 2003) rather than to pure tones. Thus, the complexity of sounds generated by vessels and the relative behavioural response by tuna did not allow us to exclude that they can hear at different frequencies other than those reported in the current literature. The only experimental evidence on hearing thresholds for a tuna species (yellowfin, Thunnus albacares) was based on the mean values from the 2 fish tested by Iversen (1967). The greatest sensitivity of yellowfin occurs between 200 and $800 \mathrm{~Hz}$, where the mean thresholds ranged from 89 to $100 \mathrm{~dB}$ re $1 \mu \mathrm{Pa}$. This evidence concurs with that of the vast majority of fish studied to date which appear to have, apart from a few species with specialist hearing, a relatively narrow audible frequency range (Popper 2000). It thus appears reasonable that the experimental bluefin tuna in our study responded mainly to noises falling within the range observed by Iversen (1967). However, our results did not allow us to conclude that bluefin tuna cannot hear more complex sounds and high frequency bands. In the absence of playback studies such considerations are purely speculative, and further studies specifically designed to investigate the hearing capabilities of this highly migratory species are needed.

In conclusion, the results from this study show that tuna behaviour can be affected by anthropogenic sound disturbances, as has been demonstrated on other occasions (see review by Popper 2003). Specifically, tuna adopted consistent behaviour if undisturbed, while showing a change when exposed to excessive noise conditions. Although inferences cannot be made on the behaviour of wild tuna, the fact that semi-captive tuna did not show a lack of acclimation a few days after capture indicates that our experimental conditions might represent valid circumstances for testing further hypotheses on animals difficult to study in their natural environment. It would seem to be possible that local noise pollution generated by commercial and recreational traffic produces a deviation from normal behavioural activity in this species. In particu- 
lar the alteration in schooling behaviour, a key strategy for gregarious species (Kils 1986), was clearly evident in the results of the present study. Our results therefore appear to substantiate that even temporary alteration of hearing, as induced by boat noise, could threaten the fitness of the exposed fish (sensu Popper 2003).

The results reported here raise many more questions than they have answered. Future research effort should be directed towards understanding the extent to which anthropogenic disturbance can affect the biology and ecology of this economically and ecologically important pelagic fish.

Acknowledgements. We thank D. Campobello (University of Manitoba, Canada) for useful discussions and the review of final version of the ms; Engineers A. Bonanno (CNR-IAMC) and S. Aronica (CNR-IAMC) for acoustical analysis, Mr. C. Buscaino for his generous help with logistic support and Dr. G. Buffa for providing the underwater cameras. We appreciate the constructive criticism of 4 anonymous referees and Dr. Robert Feller of the University of South Carolina, that substantially improved the paper. The research has been conducted in accordance with institutional, national and international guidelines concerning the use of animals in research and/or the sampling of endangered species.

\section{LITERATURE CITED}

Bart AN, Clark J, Young J, Zohar Y (2001) Underwater ambient noise measurements in aquaculture systems: a survey. Aquacult Eng 25:99-110

Benhamou S (1992) Efficiency of area-concentrated searching behaviour in a continuous patchy environment. J Theor Biol 159:67-81

Block BA, Teo SLH, Walli A, Boustany A and 5 others (2005) Electronic tagging and population structure of Atlantic bluefin tuna. Nature 434:1121-1127

Boussard A (1981) The reactions of roach (Rutilus rutilus) and rudd (Scardinius erythrophthalmus) to noises produced by high speed boating. Proc 2nd Brit Fresh Fish Conf, Southampton

Chapman CJ (1976) Some observations on the reactions of fish to sound. In: Schuijf A, Hawkins AD (eds) Sound reception in fish. Elsevier, Amsterdam, p 241-255

Colgan P (1993) The motivational basis of fish behaviour. In: Pitcher TJ (ed) Behaviour of teleost fishes. Chapman \& Hall, London, p 31-55

Dagorn L, Josse E, Bach P (2000a) Yellowfin tuna (Thunnus albacares) associated with tracking vessels during ultrasonic telemetry experiments: contribution to the tuna/ floating object issue. Fish Bull US 99:40-48

Dagorn L, Josse E, Bach P (2000b) Individual differences in horizontal movements of yellowfin tuna (Thunnus albacares) from acoustic survey in French Polynesia. Aquat Living Resour 13:193-202

Domenici P, Blake RW (1997) The kinematics and performance of fish fast-start swimming. J Exp Biol 200: 1165-1178

Domenici P, Batty RS, Simila T (2000) Spacing of wild schooling herring while encircled by killer whales. J Fish Biol 57: 831-836

Engås A, Loîkkeborg S, Ona E, Soldal AV (1996) Effects of seismic shooting on local abundance and catch rates of cod (Gadus morhua) and haddock (Melanogrammus aeglefinus). Can J Fish Aquat Sci 53:2238-2249

Godin JJ (1997) Evading predators. In: Godin JJ (ed) Behavioural ecology of teleost fishes. Oxford University Press, Oxford p 191-236

Hawkins AD, Chapman CJ (1975) Masked auditory thresholds in the cod, Gadus morhua. J Comp Physiol A 103:209-226

Hurlbert SH (1984) Pseudoreplication and the design of ecological field experiments. Ecol Monogr 54:187-211

Iversen R (1967) Response of the yellowfin tuna (Thunnus albacares) to underwater sound. In: Tavolga WN (ed) Marine bio-acoustics. Pergamon Press, Oxford, p 105-121

Josse E, Bach P, Dagorn L (1998) Simultaneous observations of tuna movements and their prey by sonic tracking and acoustic surveys. Hydrobiologia 371/372:61-69

Keenleyside MHA (1955) Some aspects of the schooling behaviour of fish. Behaviour 8:183-248

Kils U (1986) Verhaltensphysiologie Untersuchungen an pelagischen schwarmen Schwarmbildung als Strategie zur Orienterung in umwelt-gradienten Bedeutung der Schwarmbildung in der Aquakultur. Christian-AlbrechtsUniversität, Kiel, Germany

Lutcavage M, Kraus S (1995) The feasibility of direct photographic assessment of giant bluefin tuna in New England waters. Fish Bull US 95:300-310

Magurran AE (1993) Individual differences and alternative behaviours. In: Pitcher TJ (ed) Behaviour of teleost fishes. Chapman \& Hall, London, p 442-477

Marsac F, Cayré P (1998) Telemetry applied to behaviour analysis of yellowfin tuna (Thunnus albacares, Bonnaterre, 1788) movements in a network of fish aggregating devices. Hydrobiologia 371/372:155-171

Martin P, Bateson P (1993) Measuring behaviour. An introductory guide. Cambridge University Press, Cambridge

McCauley RD, Fewtrell J, Popper AN (2003) High intensity anthropogenic sound damages fish ears. J Acoust Soc Am 113:1-5

Mork OI, Bjerkeng B, Rye M (1999) Aggressive interactions in pure and mixed groups of juvenile farmed and hatcheryreared wild Atlantic salmon Salmo salar L. in relation to tank substrate. Aquacult Res 30:571-578

Myrberg AA Jr (1980) The effects of man-made noise on the behaviour of marine animals. Environ Int 16:575-586

Oksanen L (2001) Logic of experiments in ecology: is pseudoreplication a pseudoissue? Oikos 94:27-38

Pearson WH, Skalski JR, Malme CI (1992) Effects of sounds from a geophysical survey device on behaviour of captive rockfish (Sebastes spp). Can J Fish Aquat Sci 49: 1343-1356

Pitcher TJ, Parrish JK (1993) Function of shoaling behaviour in teleosts In: Pitcher TJ (ed) Behaviour of teleost fishes. Chapman \& Hall, London, p 363-439

Polovina JJ (1996) Decadal variation in the trans-Pacific migration of northern bluefin tuna (Thunnus thynnus) coherent with climate-induced change in prey abundance. Fish Oceanogr 5:114-119

Popper AN (2000) Hair cell heterogeneity and ultrasonic hearing: recent advances in understanding fish hearing. Phil Trans R Soc Lond B 355:1277-1280

Popper AN (2003) Effects of anthropogenic sounds on fishes. Fisheries 28:24-31

Popper AN, Smith ME, Cott PA, Hanna BW, MacGillivray AO, Austin ME, Mann DA (2005) Effects of exposure to seismic airgun use on hearing of 3 fish species. J Acoust Soc Am 117:3958-3971

Romero ML (2004) Physiological stress in ecology: lessons from biomedical research. Trends Ecol Evol 19:249-255 
Sandström A, Eriksson BK, Karås P, Isæus M, Schreiber H (2005) Boating and navigation activities infuence the recruitment of fish in a Baltic Sea archipelago area. Ambio: 34:125-130

Scholik AR, Yan HY (2002) Effects of boat engine noise on the auditory sensitivity of the fathead minnow, Pimephales promelas. Environ Biol Fish 63:203-209

Schwarz AL, Greer GL (1984) Responses of Pacific herring, Clupea harengus pallasi, to some underwater sounds. Can J Fish Aquat Sci 41:1183-1192

Sharp GD (2001) Tuna oceanography—an applied science. In: Block BA, Stevens ED (eds) Tuna: physiology, ecology and evolution. Academic Press, San Diego, CA, p 345-389

Editorial responsibility: Otto Kinne (Editor-in-Chief), Oldendorf/Luhe, Germany
Sloan JL, Hare JF (2004) Monotony and the information content of Richardson's ground squirrel (Spermophilus richardsonii) repeated calls: tonic communication or signal certainty? Ethology 110:147-156

Smith ME, Kane AS, Popper AN (2004) Noise-induced stress response and hearing loss in goldfish (Carassius auratus). J Exp Biol 207:427-435

Smith RJF (1997) Avoiding and deterring predators. In: Godin JJ (ed) Behavioural ecology of teleost fishes. Oxford University Press, Oxford, p 163-190

Westerberg M, Staffan F, Magnhagen C (2004) Infuence of predation risk on individual competitive ability and growth in Eurasian perch, Perca fluviatilis. Anim Behav 67:273-279

Submitted: September 28, 2005; Accepted: June 15, 2006

Proofs received from author(s): January 22, 2007 